\title{
REGULACIÓN DEL CAPITAL: A FAVOR Y EN CONTRA
}

\section{CAPITAL REGULATION: FOR AND AGAINST}

Carlos Díaz Gómez: Universidad de Alcalá de Henares. Madrid (España) carlos_diazgomez@yahoo.com

\section{CURRÍCULUM VITAE}

Doctor en Filosofía por la Universidad Complutense de Madrid (España) con Premio Extraordinario, Licenciado en Derecho por la Universidad Complutense de Madrid (España) con Premio Extraordinario, Licenciado en Altos Estudios Constitucionales con Premio Extraordinario y Profesor de la Universidad Complutense de Madrid (España). Autor de numerosos libros y artículos en revistas especializadas y universitarias.

\section{RESUMEN}

La liberalización del mercado de capitales de los últimos veinte años ha traído consigo turbulencias bursátiles y monetarias que han afectado tanto a los países industrializados como a los países en desarrollo. Hasta hace poco se pensaba que este aspecto de la globalización era un coste que merecía la pena pagar para lograr una eficiente asignación de los recursos mundiales. Este análisis sobre el tema es de asequible lectura al tiempo que riguroso sobre las cuestiones más importantes de la economía internacional actual. En él se exponen los recientes acontecimientos 
acontecidos en Asia e Iberoamérica. Desde la crisis de la deuda iberoamericana, la prudencia fiscal y monetaria se ha convertido en la nueva ortodoxia de aquellos gobiernos que quieren recoger los beneficios procedentes de su participación en el nuevo mercado global. Estos sueños se vieron interrumpidos por la reciente turbulencia asiática que comenzó con las devaluaciones obligadas del Baht tailandés en julio de 1997. Lo que inicialmente se percibía como un correctivo del tipo de cambio sobrevalorado de un país menor, se transformó rápidamente en un huracán financiero que amenazó con engullir a las economías industrializadas. Hoy, la globalización se ha convertido en el enemigo de gobiernos tan dispares como los de Rusia y Malasia. Las crisis financieras que golpearon a Asia hace dieciséis meses han suscitado una vez más la cuestión de si es posible una razonable estabilidad económica en un mundo con mercados de capitales integrados.

\section{PALABRAS CLAVE}

Liberalización - Capitalismo - Mercado - Globalización - Economía

\section{ABSTRACT}

The liberalization of capital markets in the last twenty years has brought stock and monetary shocks have affected both the industrialized and developing countries. Until recently it was thought that this aspect of globalization was a cost worth paying to achieve an efficient allocation of global resources. This analysis on the subject is affordable while rigorous reading about the most important issues of today's international economy. It presents recent developments have occurred in Asia and Latin America. From the Latin American debt crisis, monetary and fiscal prudence has become the new orthodoxy of those governments who want to reap the benefits from their participation in the new global market. These dreams were interrupted by 
the recent Asian turmoil that began with the forced devaluation of the Thai baht in July 1997. What was initially perceived it as an overvalued exchange rate of a minor country, quickly became a financial hurricane that threatened to engulf the industrialized economies. Today, globalization has become the enemy of governments as diverse as Russia and Malaysia. The financial crisis that hit Asia sixteen months ago have once again raised the question whether it is possible a reasonable economic stability in a world of integrated capital markets.

\section{KEY WORDS}

Liberalization - Capitalism - Market - Globalization - Economy

\section{ÍNDICE}

1. Introducción

2. Reflexiones históricas sobre los movimientos de capitales

3. Bibliografía

\section{TEXTO:}

La liberalización del mercado de capitales de los últimos veinte años ha traído consigo turbulencias bursátiles y monetarias que han afectado tanto a los países industrializados como a los países en desarrollo. Hasta hace poco se pensaba que este aspecto de la globalización era un coste que merecía la pena pagar para lograr una eficiente asignación de los recursos mundiales. 
Los recientes acontecimientos acaecidos en Asia y en Iberoamérica pusieron en cuestión el liberal "consenso de Washington" y propiciaron una revisión de la regulación de los flujos de capital como medio para garantizar la estabilidad. En Regulación del capital: A favor y en contra un historiador, un ex ministro de hacienda británico y tres economistas procedentes de la totalidad del espectro intelectual aportan sus apreciaciones sobre la conveniencia de controlar los flujos financieros transfronterizos. Las malas políticas económicas, la corrupción y los pánicos financieros siempre aparecen como elementos destacados entre las causas de las crisis monetarias. Los autores analizan las razones que explican este hecho, así como su relación con la regulación de los movimientos de capital.

Regulación del capital: A favor y en contra es un análisis de accesible lectura al tiempo que riguroso de algunas de las cuestiones más importantes de la economía internacional actual. De lectura obligada para todo aquel que pretenda comprender la Aldea Global en continua transformación en la que vivimos hoy.

Nota: Esta es la traducción de la introducción y del primer trabajo contenido en Capital Regulation: For and Against, publicado originalmente en Londres en el mes de febrero de 1999 por The Social Market Foundation. The SMF cede gustosamente sus derechos de copyright referidos a la publicación original para fines educativos y no comerciales exclusivamente, con la sola exigencia de que se haga constar explícitamente en cualquier eventual publicación que tal Fundación no se hace responsable de cualesquiera imprecisiones presentes en la traducción en lengua castellana.

\section{Introducción}

A lo largo de la historia, tanto los políticos como la gente corriente han percibido los mercados financieros con una mezcla de desconfianza y de temor. La imaginación 
popular ha venido asociando a los banqueros con un poder ilimitado consecuencia de su control sobre el dinero en un mundo lleno de hambre y de codicia. La presencia de fortunas creadas y perdidas en cuestión de horas durante manías especulativas y bruscas caídas bursátiles ha contribuido en no poca medida a crear la idea de unos mercados de divisas semejantes a "casinos glorificados". Más recientemente, los financieros han sido especialmente vituperados por aquellos gobiernos cuyos caros planes de ingeniería social han saltado por los aires a consecuencia de los colapsos monetarios y de las crisis de la deuda.

Desde la crisis de la deuda iberoamericana, en cambio, la prudencia fiscal y monetaria se ha convertido en la nueva ortodoxia de aquellos gobiernos que quieren recoger los beneficios procedentes de su participación en el nuevo mercado global. Los primeros noventa conocieron esfuerzos sin precedentes para endurecer la disciplina financiera por parte de los antiguos rezagados de la economía global, que fueron recompensados con entradas de capital desconocidas desde el siglo XIX. La crisis Tequila de 1994 fue rápidamente asumida como un revés temporal y los flujos de capitales dirigidos hacia los países emergentes no cesaron, extendiéndose incluso a prestatarios de alto riesgo tales como el gobierno ruso. Parecía que había llegado una nueva "era global del capitalismo", un tiempo en el que de nuevo los fondos habrían de fluir y llevar el desarrollo a nuevas tierras asegurando en el proceso a los ahorradores de los países ricos rentabilidades espectaculares.

Estos sueños se vieron interrumpidos por la reciente turbulencia asiática que comenzó con las devaluaciones obligadas del Baht tailandés en julio de 1997. Lo que inicialmente se percibía como un correctivo del tipo de cambio sobrevalorado de un país menor, se transformó rápidamente en un huracán financiero que amenazó con engullir a las economías industrializadas. Hoy, la globalización se ha convertido en el enemigo de gobiernos tan dispares como los de Rusia y Malasia. Prestigiosos 
economistas de la talla de Paul Krugman se han sumado a las voces que se alzan en contra de lo que perciben como los excesos del mercado financiero mundial.

Frente a este comportamiento perverso de "el casino global", una de las cosas que se proponen consiste en poner restricciones a los flujos financieros transfronterizos, y ese es el tema que trata de abordar el conjunto de trabajos que aquí se presenta. Se suma a una voluminosa y creciente literatura sobre las ventajas y los inconvenientes, y sobre la posibilidad efectiva de los controles de capitales en el contexto de la búsqueda actual de un sistema viable y estable de instituciones monetarias globales.

Las contradicciones fundamentales inherentes al diseño de una arquitectura financiera internacional eran bien conocidas por los economistas mucho antes de las recientes turbulencias de los mercados de divisas. En los años sesenta, el grupo Bellagio trazó su famoso triángulo, que muestra la inconsistencia entre las tres características deseables de un sistema financiero mundial -ajuste, liquidez y estabilidad.

Los tipos de cambio fijados de forma rígida ofrecen el firme compromiso que hace posible a un tiempo la movilidad de capitales sin restricciones y la ausencia de especulación, a cambio de renunciar a la política de estabilización. Los sistemas basados en la flotación dejan libre la política monetaria y los flujos financieros, pero llevan a una considerable volatilidad cambiaria, como ha puesto de manifiesto la experiencia internacional acumulada desde los años setenta. Por último, las paridades fijas pero ajustables resultan insostenibles en ausencia de restricciones a los movimientos especulativos de capitales.

En última instancia, las preferencias de los responsables de diseñar e implementar la política económica han de regirse por el modo en que perciban los costes y beneficios que la elección de una de las dos distorsiones comporta. Los mercados financieros se 
caracterizan por la asimetría en la información (de hecho, algunos creen que esa es la razón de su existencia), lo cual los hace altamente volátiles y sensibles a las noticias. La cuestión consiste por tanto en elegir entre corregir las ineficiencias que surgen de la relación del prestatario/prestamista con las restricciones a la libertad de comercio (otra restricción), o bien aprender a vivir en nuestro "mejor de los mundos posibles".

Los defensores del laissez faire generalmente consideran que las distorsiones introducidas por la regulación pesan más que lo que ellos entienden como los en gran medida inevitables costes de la volatilidad financiera. De acuerdo con este criterio, la misión principal del gobierno consiste en garantizar que no se "eche más leña al fuego" con errados intentos dirigidos a rescatar a prestamistas irresponsables o con la pretensión de mantener tipos de cambio fijos insostenibles.

Los partidarios de la regulación, por otro lado, han llamado la atención sobre la cuestión de la "salida rápida" presente en la actitud del inversor moderno respecto de su tenencia de activos. Lo cual les parece una distorsión "opcional adicional" de los mercados mundiales de divisas, que puede eliminarse con un relativamente pequeño coste social mediante controles de capitales que aseguren una conducción ordenada de la negociación de activos financieros.

Las aportaciones contenidas en este volumen proceden de todo el espectro intelectual. Robert Skidelsky presenta un análisis histórico de los acuerdos monetarios internacionales y se ocupa de la cuestión de los controles de capitales en el contexto que distingue entre economías centrales y periféricas. Nigel Lawson defiende la libertad sin restricciones de negociar con divisas, sobre la base de que eso disciplina a los gobiernos irresponsables. John Flemming pasa revista a una serie de argumentos recientes en la literatura académica a favor y en contra de la regulación. Meghnad Desai destaca la importancia de los flujos de capital para el desarrollo. Paul Davidson ofrece sus argumentos a favor de un plan de acuerdo mundial de 
compensación keynesiano que, según él, puede ocuparse del "capitalismo de casino" preservando al mismo tiempo la libertad de invertir recursos reales en todo el mundo.

\section{Reflexiones históricas sobre los movimientos de capitales}

Las crisis financieras que golpearon a Asia hace dieciséis meses han suscitado una vez más la cuestión de si es posible una razonable estabilidad económica en un mundo con mercados de capitales integrados.

i.

Es preciso cierto compromiso entre eficiencia y estabilidad, dinamismo y seguridad para que un sistema capitalista sea socialmente aceptable. Si los flujos especulativos predominan sobre los flujos de inversión, pasaremos de una economía y una sociedad abiertas a controles nacionales y bloques autárquicos. El principal precedente histórico -los años treinta- no es muy sugerente. Keynes escribió en 1936: «Puede que los especuladores no hagan daño en tanto que burbujas en una corriente de empresas sólidas. Pero la situación es seria cuando la empresa se convierte en la burbuja que flota sobre el torrente especulativo. Cuando el desarrollo del capital de un país se convierte en el subproducto de las actividades de un casino, es probable que el trabajo allí realizado resulte ser una chapuza» (Keynes, 1936, p.159). Así que garantizar una estabilidad razonable de las condiciones económicas es una cuestión de la mayor importancia social.

No debemos, sin embargo, exagerar la importancia de los acontecimientos dramáticos. Cuando Keynes escribía, tenía de fondo el panorama de una depresión 
mundial -la más importante de cuantas habían golpeado hasta entonces al mundo moderno-, y hoy nos hallamos muy lejos de aquellos días. En términos globales, el colapso financiero de Asia oriental no ha pasado de ser una "burbuja" en la "corriente de empresas sólidas". Sus efectos sobre los países centrales del mundo capitalista han sido hasta ahora poco importantes. (El estancamiento de Japón fue en varios años anterior a los acontecimientos de 1997-98). En la última era de movimientos de capitales a nivel global, que precedió a la Primera Guerra Mundial, el problema era, también, esencialmente periférico. Entonces fue Iberoamérica el escenario que presenció lo que Kindleberger llama manías, pánicos y cracs. Los países centrales de la economía mundial eran mucho más estables. Las cosas dejaron de ser así en el periodo de entreguerras; de ahí la Gran Depresión. La especulación ha venido históricamente teniendo efectos desoladores a nivel local, o sectorial. Su capacidad de hacer daño mundialmente se ha visto reducida a muy pocos episodios.

Desde el resurgimiento de un mercado de capitales global en los años setenta, la especulación ha adoptado la forma de ataques contra monedas, y este ha sido el principal objeto de estudio de la literatura monetaria internacional. La conclusión más importante a la que se ha llegado es que el tipo de cambio es un precio de un activo que refleja, como cualquier otro precio, las expectativas de ganancias o pérdidas de capital de los inversores (Eichengreen, 1994, p. 1). Puestas las cosas así, se considera que la movilidad internacional de capitales es incompatible con los tipos de cambio fijos. Ciertamente, los intentos realizados por las autoridades nacionales desde los años setenta para "fijar" o "estabilizar" o "limitar las fluctuaciones de" los tipos de cambio a la vista de los masivos flujos de capital han tendido a desvanecerse, a veces de forma dramática, como en la crisis del mecanismo de cambios del SME de 1992.

Al mismo tiempo, el argumento de que un tipo de cambio flexible permitiría a los países limitar la especulación desestabilizadora contra sus monedas, logrando así 
una mayor estabilidad de facto para sus tipos de cambio, no ha funcionado muy bien. La denominada "hipótesis de los mercados eficientes" fue puesta en entredicho por las fuertes oscilaciones -y prolongadas desalineaciones- del precio en dólares del yen y del marco en los años ochenta y noventa, a pesar de que los diferenciales de tipos de interés predecían solamente pequeñas variaciones (véase Krugman, 1989, cap. 3). Semejante intensidad en la volatilidad del tipo de cambio hace mucho daño al comercio mundial.

Así que parece que no podemos escapar de esta situación: los tipos de cambio estables son buenos para el comercio y un mercado de capitales global es bueno para la inversión, y ambos favorecen el crecimiento a largo plazo. Pero son incompatibles, puesto que en un mundo con movilidad de capitales ilimitada, los tipos de cambio no se pueden estabilizar ni fijándolos ni dejándolos flotar.

¿Cómo podemos entonces quedarnos con lo mejor de ambas situaciones? Quisiera aportar algunas reflexiones históricas. Comienzo por plantear por qué bajo el patrón oro anterior a 1914 la libertad de exportación de capitales no dio lugar a crisis monetarias. A continuación, pongo sobre la mesa la siguiente cuestión: ¿por qué la mayoría de los economistas y de los gobiernos aceptaron entre los años treinta y los años setenta la necesidad de establecer controles a los movimientos de capital? Termino considerando la posibilidad de plantear una vez más nuestro deseo de lograr a un tiempo tipos de cambio estables y mercados de capitales integrados.

ii.

El patrón oro continúa siendo un misterio en la historia de las relaciones monetarias internacionales (Eichengreen, 1985; Bordo y Schwartz, 1984). En su periodo clásico, que se extendió aproximadamente desde 1880 hasta 1914, dotó al mundo de un sistema de tipos de cambio fijos que no precisó ser defendido mediante controles de 
capitales, restricciones a la importación o un apoyo internacional sistemático. Aunque en la era del patrón oro hubo muchas crisis bancarias, rara vez desembocaron en crisis monetarias, salvo en la periferia iberoamericana. En palabras de hoy, las paridades fijas resultaban enteramente creíbles. Todo esto a pesar del hecho de que los flujos internacionales de capital llegaron a ser muy importantes como porcentaje del PIB, mayores de lo que lo son en la actualidad: el Reino Unido, por ejemplo, exportó en 1913 el 9 por ciento de su renta nacional. Conviene recordar también que no era preciso más de un minuto para poner en contacto a las bolsas de Londres y Nueva York.

En teoría, bajo el patrón oro la balanza de pagos se auto ajustaba de forma automática y simétrica, vía mecanismo de Hume de flujo-especie-precio. Los precios interiores caerían en los países que estuviesen perdiendo oro y aumentarían en los que lo estuviesen ganando, restableciendo el equilibrio de sus balanzas de pagos. En realidad, no había nada de automático en el ajuste. Los países con superávit podían esterilizar las entradas de oro, y los países con déficit endeudarse en divisas. De este modo, el mecanismo de ajuste de "flujo-especie-precio" quedaba bloqueado en ambos sentidos.

Aunque los déficit y superávit por cuenta corriente persistieron, las crisis de balanza de pagos fueron poco frecuentes. Lo cual tenía su explicación en el hecho de que los países con superávit exportaban capital y los deficitarios lo importaban. Pero no había nada de automático en este proceso. Los préstamos se atienden (pago de intereses y devolución del principal) con exportaciones. Si tales préstamos se utilizan para financiar consumo corriente o fugas de capital, o las inversiones en las que se materializan fracasan, es probable que no puedan devolverse y que la corriente de capital se vea interrumpida. De hecho, hubo muchos préstamos fallidos, especialmente en Iberoamérica, pero esto no hizo que el motor inversor global se parase. 
Centrándonos ahora en las condiciones interiores, Eichengreen ha señalado que las paridades fijas resultaban creíbles porque a los gobiernos no les preocupaba el desempleo. Sostiene que «se estaba lejos de la comprensión cabal de las conexiones entre la política monetaria y la economía interior» (Eichengreen, 1994, p. 43). En realidad, se comprendían bastante bien para lo que importaba, ya que el desempleo no persistía. Por emplear la imagen de Krugman, las economías podían caer, pero se ponían de nuevo en pie. Eichengreen pisa terreno más firme cuando señala como causa de la indiferencia del gobierno hacia el desempleo la limitación del sufragio y la debilidad de los sindicatos. Pero el misterio de la no persistencia del desempleo permanece.

Charles Kindleberger ha tratado de dilucidar el misterio del patrón oro señalando la existencia de una única, moneda preeminente, libra esterlina (Kindleberger, 1973, y muchas publicaciones posteriores). Su tesis es que la fácil disponibilidad de libras bien en forma de flujos de capital hacia el exterior, déficit comercial británico o préstamo "de última instancia" desde Londres-, unido a su aceptabilidad única, hizo que no fuese difícil para el resto del mundo mantener tipos de cambio fijos con la libra, al tiempo que limitaba los aranceles y abominaba de los controles de capital. El sistema se vino abajo cuando en el periodo de entreguerras comenzó la competencia entre monedas. En realidad, parte de las funciones de "liderazgo" a las que Kindleberger se refiere eran compartidas antes de 1914 por el Reino Unido, Francia y Alemania. Los tres países eran fuentes principales de préstamos extranjeros, así como mercados de importación de primer orden; sus monedas no fueron monedas "de reserva", en el sentido en que lo fue el dólar después de 1945, puesto que todos los países de más peso se hallaban dentro del patrón oro.

Sí desempeñaba, en cambio, Londres un papel único, que consistía en ejercer de centro de compensación del comercio internacional. Puesto que el Reino Unido, 
como país de más peso en el comercio mundial, participaba en tantas redes comerciales, y dado que era Londres el lugar indiscutible donde mantener fondos a corto plazo, lo normal era realizar los pagos internacionales mediante transferencias de saldos bancarios depositados en Londres. Lo cual hizo de la libra el vehículo principal, la divisa en que realizar tanto los pagos como las inversiones internacionales. Fue la ausencia de divisas alternativas lo que redujo el componente especulativo de los flujos de dinero a corto plazo.

A Kindleberger debemos una importante puntualización, que consiste en señalar que el éxito del patrón oro dependía de determinados elementos estructurales, o coyunturales, que se dieron cita antes de 1914 y que no se han vuelto a repetir desde entonces. Lo cual significa que el patrón oro "clásico" estaba sometido a menor tensión que los sistemas de tipos de cambio fijos posteriores.

Respecto de esta cuestión, hay que señalar que en aquellos días había muchos más precios anclaje internacionales de los que existen en la actualidad. La elevada ratio de bienes comercializables a bienes no comercializables, la estructura del comercio de mercancías, la baja participación de los servicios no comercializables en los PIB, todo ello contribuía al cumplimiento de la "ley del precio único". La inercia de precios tan característica de las modernas economías industriales apenas había nacido aún, o se hallaba en su infancia. En consecuencia, los niveles de precios de los países participantes en el comercio mundial eran menos proclives a divergir ex ante, y a tener por tanto que ajustarse ex post (Krugman, 1989, p. 9f; Triffin, 1968, p. 14). Lejos de la combinación actual de integración del mercado de capitales y de precios no competitivos.

¿Y en cuanto a los salarios? El grado de flexibilidad salarial en países como el Reino Unido con anterioridad a la Primera Guerra Mundial se exagera, y ciertamente se redujo con el desarrollo de los sindicatos. La caída de los precios unida a los rígidos 
salarios monetarios condujo a un creciente desempleo. De importancia mucho mayor a la hora de suavizar los ajustes fue la movilidad laboral transcontinental. Entre 1881 y 1915, 32 millones de personas abandonaron Europa, aproximadamente el 15 por ciento de su población. El 60 por ciento con destino a los Estados Unidos. La enorme caída en los costes de transporte permitía a los europeos sin trabajo emigrar hacia el Nuevo Mundo. Los movimientos de población se vieron acompañados de flujos de inversión dirigidos al desarrollo de nuevas tierras: el inversor y el comerciante siguieron los pasos del colono. Este fue el doble movimiento que hizo posible la superación del problema "keynesiano" al final de la centuria (Cairncross, 1953, cap. 7).

El carácter de los flujos comerciales, de inversión y población tenía su origen en el hecho de que el mundo estaba dividido en el "centro" de los países desarrollados y la "periferia" de los subdesarrollados. El capital fluía desde las áreas ricas en capital de la Europa occidental hacia las áreas escasas en capital con el fin de explotar sus recursos, sobre todo en forma de inversiones en ferrocarriles, empresas de energía eléctrica, gas y agua e industrias extractivas. Los instrumentos principales empleados en la materialización de tales inversiones consistieron en compras de activos físicos (IED) y adquisiciones de bonos gubernamentales, ferroviarios y municipales a largo plazo.

Este tosco pero eficaz mecanismo de ajuste ayuda a explicar las prácticas monetarias y fiscales de aquellos años. Los presupuestos eran pequeños porque la migración limitaba las demandas sociales. Los déficit presupuestarios financiados con dinero una fuente clave de especulación monetaria bajo un sistema de tipos de cambio fijoseran, salvo en tiempo de guerra, totalmente desconocidos.

Por supuesto, la relación entre el patrón oro y las reglas fiscales y monetarias era recíproca. Los países se obligaban a sí mismos a realizar pagos en especie con el fin 
de controlar y limitar la creación de crédito, logrando de este modo que la inversión extranjera fuese menos arriesgada. Mas las circunstancias del momento hicieron relativamente fácil el mantenimiento de la convertibilidad. Como Williams señala: «El patrón oro internacional anterior a 1914 dotó de estabilidad añadida a un mundo que ya estaba básicamente en armonía» (D. Williams, q. Aldcroft, 1977, p. 166). Esta descripción a grandes trazos de la estructura del mundo del patrón oro precisa completarse haciendo referencia a su estabilidad y a la naturaleza de sus instituciones. Ni la propiedad privada en el interior ni el imperialismo en el exterior habían sido hasta entonces puestos en cuestión. El respeto que inspiraban los contratos de deuda gozaba de reconocimiento universal. La naturaleza imperialista, o cuasi imperialista, de las relaciones centro-periferia unía a los centros metropolitanos con sus territorios dependientes a través del comercio, la inversión, la población y las relaciones monetarias. Hacia 1914, el 70 por ciento de los préstamos británicos se dirigía hacia el imperio, con el fin de minimizar el riesgo de impago. Los territorios dependientes se hallaban unidos a los principales países del patrón oro a través de cajas de conversión. La facilidad de compensación multilateral, que economizaba en el uso del oro para fines equilibradores de balanzas de pagos, dependía de la existencia de estos mecanismos de transmisión. «India, que absorbía aproximadamente el 40 por ciento del total de los déficit británicos [en 1910], continuó siendo la clave del sistema de pagos del Reino Unido, manteniendo fuertes superávit exportadores...con muchos de los acreedores británicos de aquellos días». El nivel de las exportaciones de capital del Reino Unido y su capacidad de mantener una política de importaciones libres dependía del aumento de su superávit con la India (Kenwood y Lougheed, 1992, p. 98).

La era del patrón oro fue, sucintamente, un periodo cosmopolita de calma antes de las tormentas nacionalistas y colectivistas del siglo XX. Shackle lo denomina «la era moderna de los Antoninos» (Shackle, 1967, p. 133). 
Iberoamérica era la menos estable de las regiones. En parte, debido a su dependencia de un número limitado de bienes de exportación cuyos precios fluctuaban violentamente; en parte, debido a sus inestables condiciones políticas. Los gobiernos iberoamericanos o los municipios incumplían con frecuencia las obligaciones establecidas en sus emisiones extranjeras de bonos, a lo que seguían revoluciones, brotes inflacionarios o un colapso de los precios de exportación. Hacían su aparición entonces otra vez los recaudadores de deuda, con reestructuraciones y préstamos nuevos. Se restablecían las políticas ortodoxas, y tan pronto como se reiniciaba el servicio de los bonos, volvían los inversores, aparentemente con el mismo entusiasmo pese a sus pérdidas. Pero los problemas iberoamericanos rara vez tenían repercusiones serias en los países centrales. La excepción fue la crisis de 1890, cuando Argentina incumplió en el pago de sus emisiones en manos de Baring Brothers, y el Banco de Inglaterra se vio obligado a pedir oro a Francia y Rusia para defender la libra y evitar un "drenaje" del oro nacional. Lo decisivo de todo esto era que el patrón oro era estable en el centro, inestable en su periferia iberoamericana. A este respecto, no es del todo distinto del mundo actual. Normalmente, las crisis monetarias golpeaban a los países de segunda clase, no a los de primera.

iii.

Para comprender por qué desde los años treinta a los años setenta los gobiernos favorecieron la restricción de los flujos internacionales de capitales privados, hemos de comprender el papel que se asignaba a los gobiernos en las causas de la Gran Depresión de 1929-1932. Por primera vez -parecía- los flujos internacionales de capitales habían arruinado la estabilidad de los países centrales del mundo capitalista. Sin embargo, se trataba de una conclusión precipitada. No fue la especulación internacional contra ciertas monedas lo que causó la Gran Depresión. Esta tuvo su origen, de hecho en gran medida consistió, en el colapso de la economía de los Estados Unidos, lo cual se debió a condiciones interiores poco sólidas y a 
errores políticos. Las "huidas de capital" del sistema bancario de los EE UU fue un fenómeno interior, no exterior. El colapso de Europa, en concreto de Alemania, y de las zonas periféricas situadas en Iberoamérica tenía su origen en la huida de fondos extranjeros. Pero también en este caso las causas subyacentes fueron condiciones interiores poco sólidas y errores políticos. Como muestra la historia del patrón oro clásico, si la "inducción a invertir" ha de triunfar sobre la "preferencia por la liquidez", en los inversores ha de pesar más la esperanza que el miedo. Y eso depende del modo en que los países gestionen sus políticas internas y de sus relaciones mutuas. El error de los estadistas de los años veinte consistió en restaurar el patrón oro y la movilidad internacional de capitales sin considerar las condiciones que habían hecho de tal combinación un acierto.

La guerra terminó con elevadas, y dispares, tasas de inflación, en algunos casos de hiperinflación, y su consecuencia inevitable, tipos de cambio flotantes -similar a lo que sucedió en los años setenta. El comercio era, en frase de Lloyd George, como «jugar al billar en un trasatlántico». Además, con el desarrollo de la capacidad manufacturera de los países periféricos, orientado a la sustitución de importaciones, las estructuras comerciales prebélicas se habían visto profundamente alteradas. Con la eliminación de la inflación, los países centrales fueron retornando al patrón oro entre los años 1924 y 1930. Se estabilizaron los niveles de protección arancelaria y se reiniciaron los movimientos internacionales de capitales a gran escala, sustituyendo los EE UU al Reino Unido en su papel de principal prestamista.

Pero estos flujos llevaban ahora aparejada una prima de riesgo, como consecuencia de que las paridades restauradas no resultaban del todo creíbles. El espectro del bolchevismo fue pronto exorcizado de Europa central y oriental. Pero la amenaza al sistema de propiedad privada procedente de movimientos socialistas recientemente acrecentados continuó siendo un potente y, en algunos países europeos, decisivo factor determinante de la política. En el Reino Unido, el coste en desempleo y en 
conflicto industrial resultante del intento puesto en práctica con éxito entre 1920 y 1922 de reducir los salarios nominales hizo tomar al gobierno la determinación de no aventurarse nunca más por esa vía. Al mismo tiempo, el cierre del escape migratorio -entre las dos guerras, los EE UU no absorbieron más allá de 2,5 millones de inmigrantes, comparados con los 27 millones correspondientes al periodo 1880-1914había hecho aumentar la tensión y la demanda de protección social en toda Europa. Desde mediados de los años veinte, las operaciones fiscales y monetarias del Estado, que habían aumentado mucho a consecuencia de la guerra, se dirigían cada vez en mayor medida a preservar la paz social y la estabilidad empresarial, a expensas de los objetivos prebélicos de presupuestos anuales equilibrados y dinero sólido. Lo cual abrió una inconsistencia entre las condiciones del equilibrio interno y externo que no se ha cerrado del todo desde entonces. Significaba que el intento, vía convertibilidad oro, de restaurar los anclajes internacionales de precios estaba llamado a fracasar. Los países podían ahora perder el paso en sus políticas de salarios y precios, siendo preciso practicar los ajustes ex post. Lo cual planteó explícitamente el problema, que pudo sortearse mejor al no comprenderse del todo cómo funcionaba el patrón oro anterior a la guerra, de quién había de ajustarse a quién.

El problema de la reconciliación entre el equilibrio interno y externo se vio muy agravado a consecuencia del gran volumen alcanzado por las deudas bélicas, que incluía las reparaciones alemanas, y el mantenimiento de un conjunto de tipos de cambio desalineados. Era el resultado del modo particularista y descoordinado en el que los países habían ido retornando al patrón oro. El Reino Unido insistió en 1925 en volver al oro a su paridad prebélica con el dólar. En 1926, Francia "devaluó" el franco con respecto a la libra y el marco; como consecuencia de lo cual se inició una tendencia a que el oro fluyese desde Londres y Berlín hacia Nueva York y (después de 1928) hacia París. 
La existencia de desequilibrios de balanza de pagos no corregidos confirió a los flujos de capital su carácter especulativo. Con anterioridad a 1914, los países importadores de capital tenían superávit comerciales con los exportadores de capital. Después de la guerra esta situación se invirtió. Alemania, que había sido un gran exportador de capital antes de la guerra, se convirtió en un importador neto. Los préstamos americanos, y en menor medida los británicos, todavía se dirigían hacia los países subdesarrollados; pero en un mundo de mercados saturados de alimentos y materias primas, su capacidad de atender el pago de la deuda se vio reducida. Los préstamos internacionales de los años veinte sirvieron esencialmente para cubrir posiciones desequilibradas. Gran parte de los préstamos se consumía en el pago de reparaciones y en los excesos de gasto municipales (Alemania) y en la financiación de fondos de regulación de mercancías. El Reino Unido había liquidado un cuarto de sus inversiones exteriores para pagar la guerra, y debía grandes sumas a los Estados Unidos en concepto de deudas bélicas. Londres trató de reconstruir su posición de fuente de capital internacional mediante el arriesgado expediente de tomar prestado a corto para prestar a largo.

El carácter especulativo de los flujos monetarios y financieros se vio reforzado por la presencia de otros factores que se dieron cita en aquellos días, tales como la lucha entre los centros financieros más importantes por hacerse con las divisas bajo el patrón cambios oro; el estado de subdesarrollo del mercado de capitales de Nueva York; el exceso de préstamos concedidos por los bancos americanos; el elevado arancel estadounidense, que hizo difícil para los prestatarios europeos la devolución de sus deudas mediante la obtención de dólares; etc. Todo esto convirtió a la compensación multilateral bajo el patrón oro en más aparatosa, problemática y menos eficiente de lo que lo había sido cuando tenía su centro en Londres antes de 1914. Pero estas razones no eran tan importantes como la persistencia de tipos de cambio desalineados. En este estado de cosas, era preciso que los superávit estadounidenses se sometiesen a un reciclaje continuo por parte de sus bancos para 
impedir el colapso de la economía mundial. Cualquier interrupción de este flujo estaba llamada a desatar abrumadoras fuerzas deflacionarias tanto en Europa como en las zonas periféricas.

Antes de que la década de los años veinte llegase a su fin, gran parte del mundo tenía deudas con los EE UU que no podía pagar. Cuando el ahorro de los EE UU se desvió hacia el boom especulativo de Wall Street en 1928, la poco sólida estructura de las finanzas posbélicas se vino abajo. Quienes tenían divisas comenzaron a venderlas por oro, dando lugar a la reducción de una ya de por sí inadecuada oferta mundial de crédito. El mecanismo inversor se dio la vuelta, y el dinero comenzó a fluir desde los países con déficit hacia los países con superávit. Cuando los precios de los bienes colapsaron, el patrón oro quebró en la periferia iberoamericana con una cadena de impagos. Esta vez, el contagio se extendió a Europa, vía la raquítica estructura alemana. Durante dos años, desde 1929 a 1931, Alemania trató de equilibrar sus libros mediante una austeridad sin precedentes. El resultado fue un aumento masivo del desempleo, inestabilidad política y crisis financieras, dando lugar a un impago alemán en 1931. Un huracán deflacionario asoló el mundo cuando los inversores se lanzaron frenéticamente en pos de la liquidez. El volumen de flujos especulativos que se movilizó en ataques contra monedas con paridades fijadas al oro en olas sucesivas durante 1931, 1933 y 1936 era demasiado abundante como para que pudiese detenerse mediante créditos interbancarios: la libra esterlina se desvinculó del oro en 1931, los Estados Unidos devaluaron el dólar en términos de oro en 1933, y el franco se vio forzado a suspender su convertibilidad oro en 1936. Antes del final de este último año, sólo el dólar americano de entre las principales monedas permanecía todavía en un patrón oro modificado, y una sucesión de impagos había puesto fin a los flujos privados de inversión. No se reanudaron en cuarenta años.

Keynes sintetizó la experiencia del antiguo sistema en 1941: 
Permitía el laissez-faire el envío y la aceptación de flujos de capital con fines de refugio, especulativos o de inversión. Hasta 1914 los flujos de capital se habían dirigido desde los países acreedores a los deudores y... sirvieron para desarrollar recursos en tierras subdesarrolladas... Después de la última guerra ... gran parte de estos flujos... dejó de corresponder al desarrollo de nuevos recursos. En [periodo de la Depresión] la completa degeneración hizo su aparición y los flujos de capital se dirigían desde países en los cuales el equilibrio [de la balanza de pagos] era adverso hacia países en los que era favorable.

Su conclusión era clara:

No estamos asegurados si esta contingencia se repite después de la guerra. Los cambios sociales que afectan a la posición de las clases poseedoras de riqueza son perfectamente verosímiles o pueden muy bien suponer una amenaza en muchos países. Los lugares donde se asientan nuestras fortunas más viejas se esfumarán con la velocidad de una alfombra mágica. Fondos ociosos pueden moverse por el mundo desorganizando todo negocio regular. Nada hay más claro como que la movilidad de los fondos de capital ha de regularse. (Keynes, 1941, p. 31)

No hay duda de que fue la extensión de la inestabilidad financiera desde las potencias de segunda clase hasta las de primera lo que espoleó esta demanda de regulación de la libre circulación de capitales.

iv.

La posición de Keynes cuando en 1941 trazó su plan de Acuerdo de Compensación Multilateral se resumía en su comentario de que, bajo el patrón oro, «el proceso de ajuste es obligatorio para los deudores y voluntario para los acreedores» (Keynes, 1941, p. 28). El país acreedor tenía la opción de reducir aranceles, invertir en el 
exterior, expandir su economía interna o esterilizar -acumulando- sus excedentes. El deudor no podía sino embarcarse en la deflación y dejar que aumentase el desempleo. Keynes creía que el éxito del patrón oro anterior a 1914 había dependido de la existencia de un sistema de ajuste de facto por parte del acreedor, con pivote en Londres. En los años de entreguerras, los Estados Unidos no habían estado a la altura de sus responsabilidades acreedoras. Se habían drenado reservas del resto del mundo «para pagar a un país que se obstinaba en tomar prestado y exportar muchísimo más de lo que él por su parte estaba prestando e importando» (Keynes, 1944, p. 14).

Keynes apuntó a la «falta de confianza» como causa de la preferencia por la liquidez. Él entendía que esta propensión tenía su origen sobre todo en la incertidumbre que afectaba a la «posición de las clases poseedoras de riqueza»-un ejemplo que él utilizó en más de una ocasión. En otras palabras, la estabilidad social y política ya no podía garantizarse, ni siquiera en los países centrales; a este respecto, se habían convertido en algo similar a las repúblicas bananeras iberoamericanas. Con independencia del modo en que uno contemple los "experimentos sociales" -y Keynes consideraba algunos ciertamente más benignos que otros-, era claro que estaban llamados a comprometer seriamente a los dueños de riqueza, que podían tenerse por sus principales víctimas. Así que las sociedades tendrían que protegerse contra las fugas de capital protagonizadas por propios o extraños.

Al mismo tiempo, era un convencido de los tipos de cambio fijos, aunque precisasen ajustarse de vez en cuando. La cuadratura del círculo sería posible con la supresión de la capacidad de especulación monetaria de los titulares de riqueza. Los flujos de capital habrían de canalizarse a través de su nuevo Súper Banco, quedando de este modo excluido su potencial desestabilizador. El Banco de Compensación de Keynes descargaría automáticamente a las naciones acreedoras del deber que habían venido desempeñando en el pasado de forma esporádica y voluntaria. A un país con 
superávit que estuviese acumulando en vez de prestando reservas no se le permitiría privar de su uso a los países deficitarios, puesto que éstos dispondrían de sus correspondientes saldos acreedores hasta el nivel de sus cuotas, que vendrían determinadas por su participación en el comercio mundial.

En el sistema de Bretton Woods instaurado en 1944, se suponía que el FMI y el Banco Mundial se repartían las funciones de corto y largo plazo de los flujos de capital. Pero sus recursos eran tan escasos en comparación con las facilidades de descubierto que Keynes había dado a su Banco de Compensación, que ambas instituciones estuvieron marginadas por mucho tiempo.

v.

Tras la segunda guerra mundial, la reconstrucción de Europa y Japón corrió a cargo del contribuyente americano, no del banquero americano. El ajuste acreedor que Keynes había esperado lograr a través de las instituciones que él mismo había ayudado a establecer se produjo ad hoc como resultado de la Guerra Fría. Los préstamos comerciales exteriores sólo se reavivaron cuando a los bancos privados se les encomendó en los setenta la tarea de reciclar los excedentes de la OPEP, de modo muy similar a como los bancos estadounidenses habían reciclado los superávit norteamericanos en los años veinte. Desde entonces, han crecido de forma exponencial, y constituyen un rasgo esencial de lo que hoy llamamos globalización.

Hemos pasado también por toda la gama de impagos soberanos y de acciones masivas contra monedas por parte de los bajistas, tal y como sucedió en el colapso de 1931.

Como ya he apuntado, es cuando el centro se ve seriamente amenazado cuando hay más probabilidades de que la demanda de regulación de los movimientos de 
capitales se deje sentir con más fuerza. Cuando la inestabilidad queda confinada a la periferia, el problema de la libertad de los movimientos de capitales es obviamente menos acuciante para los gestores del sistema mundial.

La inestabilidad todavía se contempla desde un punto de vista teórico como el resultado de fundamentos poco sólidos; y es mucho más probable que ése sea el caso de los países subdesarrollados y recientemente desarrollados que el de los países cuyo desarrollo viene de lejos.

Deberíamos, por tanto, al valorar si es posible o no otra Gran Depresión, dirigir nuestra atención, no a los acontecimientos de Asia oriental (ni siquiera a los de Iberoamérica), sino a las condiciones imperantes en Europa y en los Estados Unidos, y a las relaciones entre estas dos áreas del núcleo. Del mismo modo que las guerras mundiales fueron globales porque comenzaron en el centro, la depresión global tendrá su origen aquí o en ningún sitio. Las relaciones entre el dólar y el euro serán obviamente un indicador clave de la estabilidad futura del núcleo o centro del sistema.

Los argumentos a favor de la regulación de los movimientos de capital suscitan claramente la cuestión del perjuicio que puedan causar a las condiciones actuales. Y esto suscita un juicio sobre si nuestro mundo se parece más al mundo de los años veinte y primeros treinta que conformó el criterio de los arquitectos de Bretton Woods, o a aquél anterior a 1914 en el que la movilidad internacional del capital no dio lugar a grandes problemas.

\section{Bibliografía}


Todas las referencias a Keynes están tomadas de los Collected Writings of John Maynard Keynes, publicados en inglés por Macmillan para la Royal Economic Society entre 1971 y 1989.

Robert Skidelsky

Aldcroft, D. H., (1977), From Versailles to Wall Street 1919-1929, Allen Lane.

Bordo, Michael and Schwartz, Anna, eds. (1984), A Retrospect on the Classical Gold

Standard, University of Chicago Press.

Cairncross, A. K., (1953), Home and Foreign Investment 1870-1913: Studies in Capital Accumulation, OUP.

Eichengreen, Barry, ed., (1985), The Gold Standard in Theory and History, Methuen.

Eichengreen, (1994), International Monetary Arrangements for the 21st Century, Brookings Institution.

Kenwood, A. G. and Lougheed, A. L., (1992 edn.), The Growth of the International Economy 1820-1990, Routledge. (Hay traducción española publicada en por)

Keynes, J. M., (1936), The General Theory of Employment, Interest and Money, CW, vol. 7

Keynes, J. M., (1941), 'Post-War Currency Policy', 8.9.41, CW, vol. 25.

(1944), Speech in the House of Lords, 23.5.44, CW, vol. 26. 
Krugman, P., (1989), Exchange Rate Instability, MIT Press.

Kindleberger, C., (1973), The World in Depression 1929-1939, Allen Lane.

Kindleberger, (1996), World Economic Primacy 1500-1990, OUP.

Shackle, G. L. S., (1967), The Years of High Theory: Invention and Tradition in Economic Thought, CUP.

Triffin, R., (1968), Our International Monetary System: Yesterday, Today and Tomorrow, New York. 